\title{
The Role of Information Literacy in Higher Education: An Initiative at Al Akhawayn University in Morocco
}

\author{
Best Practice Article
}

Aziz El Hassasni*

Al Akhawayn University

\begin{abstract}
This paper, part of which was presented at the 12th annual AMICAL conference at the American University in Bulgaria held in Blagoevgrad, on 29 May 2015, reports on a doctoral research project which explores the meaning and role of information literacy in higher education and lifelong learning. It also highlights an information literacy initiative at a Moroccan university, namely Al Akhawayn University in Ifrane, and how its academic library strives to promote it. Living in an age of information tsunami and technological advancement, issues of information access, evaluation, retrieval and effective use, have become significantly critical in our societies. Directing the attention to the issue of information literacy and framing the best practices on how they can be best blended into the learning process of students are of paramount importance. Like other libraries across the globe, Mohammed VI Library at Al Akhawayn University in Morocco has realized the importance of information literacy and has worked in various ways to address this issue. This paper will describe the university strategy of teaching Information Literacy to graduate and undergraduate students in a number of ways. Recommendations to improve and support this initiative, including incorporating information literacy and skills across the university's curriculum, and fostering more effective partnerships between the $\mathrm{Al}$ Akhawayn university library and the teaching faculty, will be also discussed in this paper.
\end{abstract}

\section{Keywords:}

Information Literacy; Post-Secondary Education; Role of the Post-Secondary Educator; lifelong learning; higher education; learning outcomes; collaboration.

\section{*Contact:}

Aziz El Hassani, Al Akhawayn University in Ifrane, Mohammed VI Library, Multimedia Learning Center, Morocco.

e-mail: a.elhassani@aui.ma

Nordic Journal of Information Literacy in Higher Education, 2015. (C2015 Aziz El Haasani

\section{(cc)) BY-NC} This is an Open Access article distributed under the terms of the Creative Commons Attribution Noncommercial 3.0 Unported License (http://creativecommons.org/licenses/by-nc/3.0/) 


\section{Introduction}

The tsunami of information in today's world has urged modern societies to explore and develop new intelligent search skills and behaviors while accessing and using information from different sources. Such skills are known as information literacy (IL) skills. IL has therefore become a new paradigm and the most critical sets of skills in todays and tomorrow's advanced information and communication world.

\section{Information literacy in higher education}

IL acknowledges the crucial role of information in our everyday lives and of immense importance to institution of higher education. "Given that the information revolution has immensely increased the ability to access and employ information, using various sources including information published electronically, societies are required to have certain capabilities (other than the ability to read and write) to fully utilize these resources. Scholars affirm that society requires multi-skilled learners, who are able to think critically, pose and solve problems, and become independent and lifelong learners" (Haberle, 2002, p. 22). It is also important that learners gain an understanding of the technological environment in which information resources are incorporated and used, as it is not just the finding of information, but the ability to use it that is important. Universities should provide opportunities for ensuring that all students acquire the necessary competence in knowing how to navigate the web and find quality resources, to formulate questions, to access potential sources of information, to critically evaluate information for accuracy and quality, to organize information, and finally, to use information to do something, the last and most valuable step in the process (Doyle, 1994).

The need for IL instruction is becoming continually more important due to the ubiquitous of electronic resources and the significant increase use of the internet as an information source. IL is a "set of skills which includes finding information effectively; managing the abundance of information available; thinking critically about resources; synthesizing and incorporating information into one's knowledge base; creatively expressing and effectively communicating new knowledge; using information ethically; and using knowledge to better society" (Beaubien, 2009, p. 63). IL plays a major role in higher education (ACRL, n.d.). Preparing students to become information literate and independent researchers have always been the focal goal of myriad academic institutions in the west. While many western academic institutions have successfully managed to fully incorporate IL within the corpuses of their educational systems, many developing countries continue to adopt traditional forms of education, utterly devoid from any reference to IL or critical thinking concepts.

In this paper IL is the ability to identify, locate, evaluate, and use information effectively. This definition combines critical thinking and facility with information media technology. IL stands at the core of freedom of expression and information - since it empowers citizens to understand the functions of media and other information providers, to critically evaluate their content, and to make informed decisions as users and producer of information and media content, is of immense importance to institutions of higher education. One reason is that some undergraduate students acceding university have limited background of fundamental research and information competency skills. They may not have acquired the necessary skills to effectively search for information, or evaluate, synthesize and blend ideas; or may not have learned how to use information in original work or give proper citation and reference for information used. While some students may have acquired basic computer skills to send electronic mail, navigate the web, and share files, they may not have been taught how to effectively search the Internet or effectively use library E-resources for academic research. This is where IL skills are essential and make the difference to the success of students. If these latter are given the opportunity to follow such programs, they will certainly face fewer difficulties while writing papers and doing academic research projects. Like many academic institutions across the globe, Mohammed VI Library at Al Akhawayn University is faced with the major 
challenge of making users information literate as opposed to library literate. In response to this, the strategic plan of the Library, which also serves the wider strategic plan of the university as a whole, has expanded over the past ten years from merely providing students with information into teaching them how to better utilize information resources and become lifelong readers.

\section{An Information literacy initiative at Al Akhawayn University in Morocco}

Al Akhawayn University (AUI) is an independent, public, not-for-profit, coeducational university committed to educating future citizen-leaders of Morocco and the world through a globally oriented, English-language, liberal-arts curriculum based on the American style. The University enhances Morocco and engages the world through leading edge educational and research programs, including continuing and executive education, upholds the highest academic and ethical standards, and promotes equity and social responsibility. The university serves 2072 students from its campus. Al Akhawayn University library, named Mohammed VI Library, is an oasis of information resources and services. Its mission is to serve the University's liberal arts educational system and provide access to information resources to the University community and to other researchers to enhance learning, teaching and research activities. The Library provides a growing collection of print and electronic resources, and actively engages faculty and students through various outreach activities, information literacy workshops and trainings that are designed to enrich their learning, teaching and research experiences

The collaboration between the library and the university teaching faculty at Al Akhawayn University comes through several venues. Faculty members may request library training workshops for their students; AUI students can request individualized research consultations; the university's three schools collaborate with the library in creating and uploading customized Course Guides that fits curricular needs. Mohammed VI Librarians reach out to faculty to share ways in which they can encourage their students to participate in information and research activities and better utilize the library's varied print and electronic resources. Another proved effective approach, one which promotes faculty-librarian collaboration, is the library's systematic creation of Course Guides to aid AUI students in various academic programs.

Mohammed VI Library's information literacy initiative involves teaching AUI students how to search for, find, and correctly use quality academic information made available from the library's print and electronic resources. The library has set specific objectives and actions to promote and enhance its role as a learning hub though faculty outreach initiatives and information literacy. This latter is conducted in collaboration with the coordinators and faculty of the first-year foundation programs, dubbed "FAS - Strategic Academic Skills".

Since 2007, the university library has been active in ensuring that students are provided with the necessary search skills to access and use information. Approximately, Mohammed VI Librarians facilitates more than 50 IL workshops for students each year in support of various classes and have served over 7279 students during the last six years. The focal objectives of the information instruction program at Mohammed VI Library is to:

(a) improve the ability of university students and library users to make effective use of the library resources, services, and library staff

(b) to make library users aware of the library technological search tools and teach them how to effectively use them

(c) to equip library users with the necessary skills that will enable them better evaluate and retrieve authoritative scholarly information for their research.

IL instruction at Mohammed VI Library is not offered as a credit-bearing course for undergraduate and graduate students within the curriculum on a regular basis, but as a separate 
supportive library service and comprehensive training program, which enables students to develop and acquire the necessary literacy skills to deal independently and skillfully with substantial amount of information.

Each semester, Mohamed VI Library provides a variety of instructional sessions and training workshops for sophomore Strategic Academic Skills students (FAS 0210 and FAS 1220), Race, Religion, and Minorities in the United States' graduate class (SSC 3331 / SSC 5321) and Research Methods' graduate class (SSC 3303). During each IL class, students generally attend and participate in a 30 minutes long training presentation as well as 15 minutes long practical application session. Usually, most of these library training sessions are held at the library multimedia learning center (MLC), which is a learning hub for both students and faculty, where they have a librarian-led IL instruction class. Students receive library-provided handouts to reinforce the learning process and practice on their own more effectively.

Four professional librarians, all of whom are fluent in at least 3 languages, are involved in the library instruction program, working collaboratively with the faculty in supporting bibliographical instruction at the university. Having such dedicated team of librarians, who guide the students to the best available library resources, makes the IL programme unique and complementary with other university-related academic programmes.

The IL initiative is still in its nascent stages at Al Akhawayn University Library, albeit witnessing an impressive growth and spread during the past five years. Irrespective of what future ameliorations and direction this initiative may take, however, any plans the university makes to further embed IL concepts into the wider curriculum will significantly impact the academic performance of students.

IL at Al Akhawayn University in Morocco is a user experience practice. The aim is to familiarize new students with the library services, collections, and facilities. Library orientations and tours, conducted at the beginning of each academic semester, enable students to learn more about the Library's collections, resources, services, and physical set up of the building. During these library orientation tours, students may ask questions. Tours at Mohamed VI Library are usually 10-20 minutes in length and may vary in content and format depending on the level of students. Mohammed VI Library offers newly enrolled students the opportunity to attend and participate in a very practical face-to-face introduction library workshop, designed to help them better use library resources and facilities. It includes a bibliographical instruction session which comprises instruction on the use of library resources, LC classification system, Library Online Catalog and reference sources (dictionaries, encyclopedias). Following these initial library training, a subsequent information skills training is offered to students, which includes an introduction to electronic resources (the library subscribes to about 38 database), how to effectively search EBSCO Discovery Service (OneSearch), how to access EBook collections, and how to cite sources correctly using a variety of different style guides.

The IL initiative at Mohammed VI Library has grown intensely in recent years to reach 87 instruction sessions for 1,506 students in 2012-2013. Each year, close to 95\% of all freshmen are introduced to library services through the Library/FAS collaborative IL programme in order to ensure that all AUI students become familiar with resources available to them during their first academic year.

\section{Recommendations and conclusion}

Information literacy is an essential component of general education at both the undergraduate and graduate levels. I think, Mohammed VI Library at Al Akhawayn University has succeeded into laying the foundation stone for the growth of an effective model of IL support programme 
The Role of Information Literacy in Higher Education: An Initiative at Al Akhawayn University in Morocco.

tailored to help AUI students build the necessary skills and know-how that carry forth into higher level of university education. However, and in order to succeed, this library-led IL initiative should pave the way for a university-led wider initiative to incorporate and expand IL standards across the curriculum. Likewise, the success of this initiative depends on the willingness to devise a policy, which recognizes IL, as a key skill for the development of excellent research skills at this university. 


\section{References}

ACRL, (n.d.). Information Literacy Competency Standards for Higher Education. Retrieved from http://www.ala.org/acrl/standards/informationliteracycompetency

Beaubien, S. (2009). Information literacy core competencies. Allendale, MI: Grand Valley State University.

Doyle, C. S. (1994). Information Literacy in an Information Society: A Concept for the Information Age. Syracuse. New York: ERIC Clearinghouse on Information and Technology.

Haberle, N. 2002. Developing a theoretical evaluative framework for information literacy interventions: a South African initiative. South African journal of higher education. 16(3), 21-30 